\title{
Globalization and Voter Turnout in Times of Crisis
}

Jeffrey A. Karp and Caitlin Milazzo

\subsection{Introduction}

One of the most alarming trends in democratic systems is the almost universal decline in voter turnout that has been observed in a wide range of countries. Between 1970 and 2011, average voter turnout around the world has declined by roughly 10 per cent. Declining voter turnout is often viewed as a threat to democracy because those who choose to participate in elections are assumed to have greater resources, while those who have less withdraw from the political process. Politicians who want to win elections will favour policies that deliver benefits to those who make a difference to electoral outcomes and will ignore those who choose not to participate (Bartels 2008b; Gilens 2005; Griffin and Newman 2005). Thus, systematic declines in turnout, either within or across countries, may have significant implications for the type and quality of representation citizens receive.

Previous work suggests that economic interdependence may be an important cause of the decline in voter turnout because it constrains the ability of parties and governments to address economic policy issues (Hellwig and Samuels 2007; Steiner 2010; Marshall and Fisher 2011). The constraint reduces the incentive for citizens to turn out by decreasing the potential effect of the election outcome and, therefore, voters' perception of their influence on policymaking. There are, however, a number of empirical issues that raise doubts about the generalizability of the conclusions reached by these studies. Chiefly among them is that the research is limited to a small number of advanced industrial democracies with similar economies, so we simply do not know how economic interdependence affects democratic participation in the vast number of countries where there are greater socio-economic differences. 
In this chapter, we re-examine the relationship between globalization and voter turnout. ${ }^{1}$ Specifically, we explore whether (and how) the presence of a major economic crisis mediates the relationship between economic interdependence and turnout. It is possible that a severe economic crisis intensifies the turnout-dampening effect of globalization. During times of economic crisis, the visibility of economic integration is more pronounced, which may amplify citizens' perceptions of their inability to affect policy outcomes. As a result, voters' sense of helplessness and malaise may become more pronounced in economically integrated nations during a major economic crisis. At the same time, anecdotal evidence from the current global financial crisis suggests an alternative perspective. Popular protest movements, such as Occupy Wall Street in the United States-a country that is characterized by both economic interdependence and low voter turnout-provides evidence that citizens can, in fact, be mobilized by crisis. If so, then we might expect adverse economic conditions to motivate rather than discourage citizens to become more involved in the political process.

\subsection{Participation in Times of Crisis}

Empirical research on the relationship between globalization and voter turnout frequently concludes that economic interdependence reduces turnout. For example, Gray and Kittilson (2005) find a negative relationship between globalization and turnout in their study of presidential and parliamentary elections in nineteen countries from the Organisation for Economic Co-operation and Development (OECD) between 1950 and 2000. In a study of parliamentary elections in twenty-three OECD democracies between 1965 and 2006, Steiner (2010) finds similar evidence, which leads him to conclude that economic globalization is a central cause of the general decline in turnout within established democracies. Finally, using a combination of aggregatelevel and individual-level survey data from twenty-three OECD countries since the 1970s, Marshall and Fisher (2011) argue that globalization causes voters to become indifferent between parties, which in turn reduces turnout.

Taking these findings as a starting point, there are several reasons to expect that an economic crisis will amplify the turnout-depressing effect of globalization. For example, if greater globalization means that governments have less control over their national economy, then during a crisis, government leaders will almost certainly place the blame on economic interdependence and claim they are not responsible for economic downturns. Previous research suggests that economic integration weakens the connection between economic performance and support for the incumbent government (Fernández-Albertos 2006; Hellwig and Samuels 2007). Economic performance, and the economy 
more generally, tends to be perceived as an important factor for determining vote choice and mobilizing voters (see Lewis-Beck and Stegmaier 2000 for a comprehensive review of the economic voting literature). If the presence of a crisis increases citizens' perceptions that national governments in integrated nations have little control of the economy, citizens may have less of an incentive to participate in the political process. Put differently, voters' need to participate to affect economic outcomes declines, because they perceive national governments have little ability to affect policies that will resolve the crisis.

In addition, while economic interdependence may stimulate growth (Wolf 2004), it may also produce inequality. Some believe that globalization places stress on the welfare state so that social and labour policies produce a 'race to the bottom' (Tanzi 1995). If globalization leads to greater income inequality, as some fear, than income inequality may lead to greater political inequality (Solt 2008, 2010). Socio-demographics have long been recognized as a determinant of voting (Wolfinger and Rosenstone 1980). We know, for example, that those with high levels of education and income are more likely to be engaged in the political process. This argument is based on the assumption that those who lack resources do not have the means to engage meaningfully in elections (Verba et al. 1995). Hopelessness and despair may also discourage the poorest from participating, which lowers overall turnout (Boix 2003; Solt 2008). If the presence of a major economic crisis amplifies the equality associated with globalization, then resource-poor citizens may further withdraw from the political process because they rationally conclude that there is little point to engaging in politics.

At the same time, there are many reasons why we might expect that adverse economic conditions, such as an economic crisis, will motivate the citizens who are most vulnerable to become more rather than less involved in the political process. First, adverse conditions that pose a threat may lead to a breakdown of social norms, anger, and anxiety brought about by social change. These conditions have been cited as an explanation for the rise of extreme right support in Western Europe (Arzheimer 2009). In systems that foster extreme parties, voters develop stronger attachments (Bowler et al. 1994). Past research shows that voters with strong party attachments are more likely to be interested in politics and more likely to vote (Campbell et al. 1960; Verba et al. 1979). Having a policy connection to a party can also increase the likelihood of participating (see for example Blais 2000). If an economic crisis facilitates stronger party attachments, then it may help citizens to overcome the turnout-depressing effects of globalization.

Second, even if globalization reduces the ability of national governments to address economic issues, the presence of a major crisis may encourage parties to offer distinct, and perhaps ideologically based, solutions for resolving 
the crisis. Dalton (2008) argues that party polarization or the differentiation of choices offered to voters is another important variable linking electoral institutions to political behaviour. In order to differentiate between parties on policy dimensions, voters must also be able to perceive policy differences between parties (Campbell et al. 1960; Butler and Stokes 1974). Crepaz (1990) maintains that party polarization increases the choices available to voters, which motivates citizens to participate. Indeed, he finds that polarization is associated with higher voter turnout in his study of sixteen industrial democracies. If the presence of a crisis promotes policy differences between parties, citizens may perceive that electoral choices may be more meaningful in spite of globalization, and as a result, citizens may have a stronger incentive to participate in the political process.

Finally, it has also long been assumed that citizens participate in the political process for instrumental reasons. That is, citizens are motivated to participate by their desire to influence electoral outcomes and hold governments accountable for their performance. When elections are more salient citizens are more likely to vote (Franklin 2004). The presence of a major economic crisis may raise the stakes associated with the outcome of the election-i.e., in times of crisis, citizens may be more likely to turn out to vote in order to throw the rascals out and change policy.

In sum, there are reasons why we might expect a major economic crisis to either promote or attenuate the well-documented dampening effect of globalization. In the next sections, we explore these arguments in more detail using both individual- and aggregate-level data in a large and diverse set of countries.

\subsection{Approach}

The global financial crisis of 2007-08, which many economists consider to be the worst financial crisis since the Great Depression of the 1930s, provides an ideal case study to examine these questions. The crisis was triggered by the bursting of the 'housing bubble' which peaked in 2006, with the average price of a home in the United States rising over the decade by 124 per cent (Economist 2007). The first stage of crisis was apparent in August of 2007 when investors and savers attempted to liquidate assets deposited in highly leveraged financial institutions. A year later, the financial crisis came to a head with the run on the Northern Rock Bank in the United Kingdom in September of 2008 and the collapse of the international investment bank Lehman Brothers. While governments in the United Kingdom and the United States had previously intervened to save banks that got into serious trouble, the failure of Lehman Brothers proved that no bank was 'too big to fail'. In October, the U. 
S. Congress responded by funding a $\$ 700$ billion emergency bailout. The crisis rapidly developed into a global one leading to the failure of European banks. In Iceland, all three of the country's major banks failed in 2008, leading to the largest banking collapse of any country relative to its size (Economist 2008).

Our analysis proceeds in two stages. First, we begin with an over-time comparison of globalization and turnout in a diverse set of countries. Specifically, we use aggregate data from more than 450 legislative elections in 73 countries to examine the effect of globalization and economic crisis on voter turnout between 1970 and 2011. We then examine individual-level explanations for turnout, drawing on data from the Comparative Study of Electoral Systems (CSES). As we are interested in examining how changes in economic conditions affect who participates, we examine group-based differences in participation within countries before and after the global financial crisis. To date, three CSES modules have been fielded in national election studies in over forty countries. At the time of writing, the latest release of Module 3, on 31 May 2012, was fielded in over thirty countries. Of those, about a third of the countries had run the CSES module before and after 2007, which marks the onset of the global financial crisis. This data provides us with a unique opportunity to examine changes in political behaviour in national elections across a diverse set of countries.

\subsection{Aggregate Trends in Turnout, 1970-2011}

We begin with an analysis of differences in voter turnout across a broad range of countries between 1970 and 2011. We limit the countries and elections included in the dataset in four ways. First, we include only the democratic legislative elections that occurred in countries that were classified as 'free' according to the Freedom House Index. Second, we limit the analysis to countries that held more than one free election. Third, we focus on unbroken chains of democratic elections. Therefore, if there was a breakdown of democracy (i.e., the country was not classified as 'free' for one or more years after the initial transition to democracy), we include only the elections that occur after the country is once again classified as 'free'. ${ }^{2}$ Finally, we limit the analysis to countries that are democratic in their most recent election; countries that were briefly democratic, but are no longer so are not included in the analysis. ${ }^{3}$ With these restrictions, we are left with data on 564 elections in 73 countries between 1970 and 2011. ${ }^{4}$ Despite the restrictions, the dataset extends the analyses of previous studies by incorporating countries that exhibit variation in terms of wealth, population size, the number of consecutive democratic elections, and electoral rules. 
The dependent variable, Voter Turnout, is measured as the percentage of the voting age population (VAP). ${ }^{5}$ VAP turnout is often criticized for 'inflating the denominator'-i.e., the measure of the total eligible voting age population may include individuals, such as prisoners or immigrants, who are not, in reality, eligible to vote. The inclusion of such individuals will inflate the denominator of the voter turnout (recorded turnout divided by voting age population) such that we may underestimate voter turnout (see McDonald and Popkin 2001, for a discussion of this issue). Alternatively, we could measure voter turnout as a function of the percentage of registered voters. However, it is difficult to acquire reliable data on the number of registered voters, particularly in new and developing democracies. Given that we are interested in voter turnout across contexts, we judge the VAP measure to be the safer choice.

To capture the effects of globalization, we rely on the composite globalization index compiled by the KOF Swiss Economic Institute (Dreher et al. 2008b). The index is comprised of numerous economic, social, and political indicators. ${ }^{6}$ Because the measure captures a number of different facets of globalization, it is ideal for capturing the overall effects of globalization, compared with any single measure (e.g., FDI, trade flows). ${ }^{7}$ However, we also estimate a series of supplementary analyses (presented below) where we use the economic, social, and political globalization indices, and we find substantively comparable results.

Figure 10.1 displays the lowess-smoothed trends in voter turnout and globalization between 1970 and 2010. Note the striking inverse relationship between the two trends; voter turnout has been in decline throughout the period, while globalization has been on the rise. During the 1970s, voter turnout was approximately 76 per cent. However, by the 2000s, it had declined to 67 per cent. In contrast, globalization has exhibited a parallel increase over the same period. In 1970, the average level of globalization, as measured by the KOF index, was 58. By 2011, the average increased to 68 . While these patterns by no means indicate a causal connection, the parallels are obvious, and therefore, it is perhaps unsurprising that scholars have explored the theoretical connection between these two phenomena.

To explore the relationship more systematically, we estimate a series of models where we model voter turnout as a function of globalization, economic crisis, and a number of other relevant covariates. In order to capture the effect of the global financial crisis, we include a dichotomous variable to capture the primary years affected by the crisis. While the recessions associated with the finance crisis continue today, our dataset concludes in 2011, therefore Global Financial Crisis includes the years of 2008, 2009, 2010, and 2011. Moreover, because we are interested in how the presence of a major economic crisis mediates the relationship between globalization and turnout, we include an 
Jeffrey A. Karp and Caitlin Milazzo

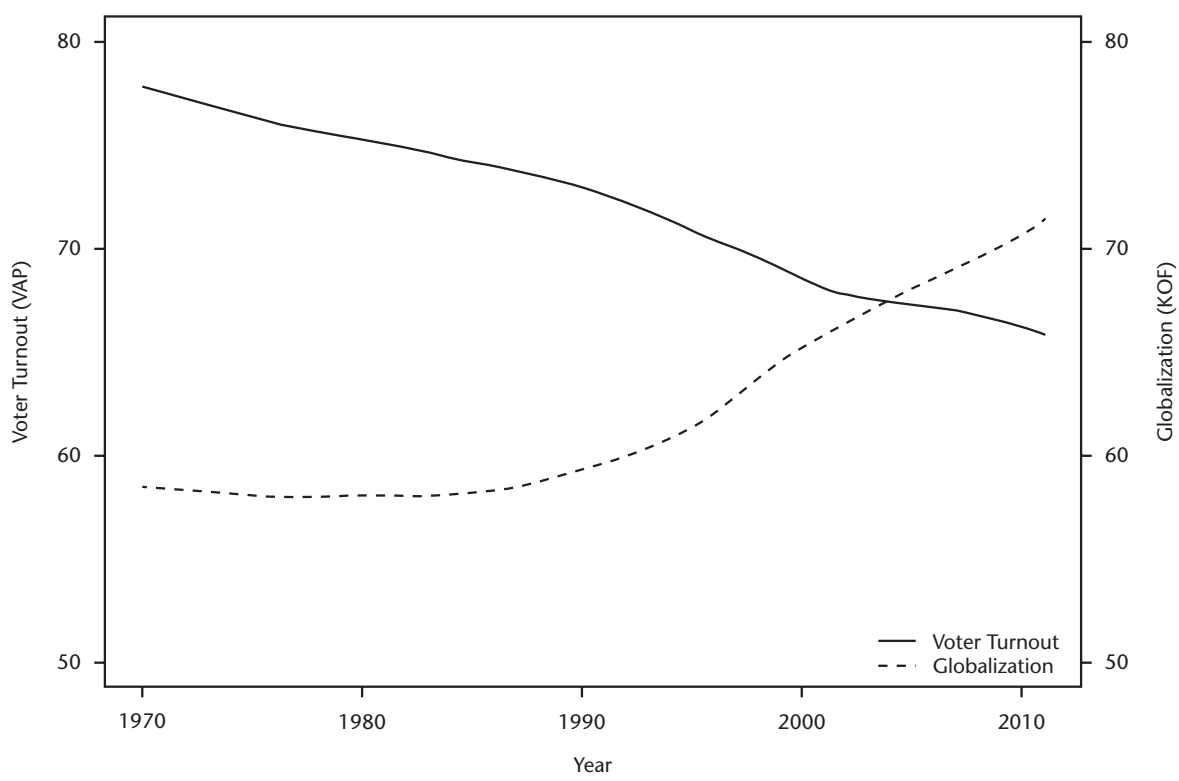

Figure 10.1. Trends in voter turnout and globalization, 1970-2011

interaction between globalization and the economic crisis variable. If the presence of the crisis exacerbates the turnout-dampening effect of globalization, then the coefficient estimates on the interacted variable will be negative. In contrast, if the crisis mobilizes citizens, the coefficient estimate will be positive.

Given that our dataset includes diverse countries, it is important that we control for additional features that might lead to higher (or lower) turnout across or within countries. ${ }^{8}$ For example, previous research suggests that features of the electoral system may promote (or depress turnout), and thus we include two dichotomous institutional variables. Compulsory Voting is coded 1 if compulsory voting laws were present and enforced, and 0 otherwise. Majoritarian System is coded 1 if the country uses a majoritarian electoral system, as such systems are traditionally characterized by lower voter turnout (Powell 1980; Jackman 1987; Franklin 2004). Beyond the institutional variables, we also control for variation in wealth, population size, and the quality and relative age of democracy. To capture the overall level of wealth, we control for the county's GDP per capita. With respect to population size, our dataset includes a number of small island states, where it may be easier to mobilize the more limited population. Therefore, we include a dichotomous variable, Small Country, which is coded 1 if the population size is less than 100,000 and 0 otherwise. Finally, we use two variables to capture the quality and age of democracy. Established Democracy is coded 1 if the country 
held democratic legislative elections prior to 1980. Level of Democracy is coded such that higher levels of the variable indicate a decline in quality of the democracy. ${ }^{9}$

Given that we have panel data (i.e., consecutive elections nested within countries), our methodological choices merit careful consideration. Specifically, our modelling choices need to address two important issues. ${ }^{10}$ First, a Wooldridge test (2002) indicates the presence of serial correlation within the data. ${ }^{11}$ This is unsurprising given that turnout in the 2011 Danish election is likely to be related to turnout in the 2007 election. In addition, there may be country-level differences beyond those discussed above that cause some countries to have higher (or lower) turnout. If so, then the errors of observations within countries are correlated, such that some countries are characterized by higher/lower variance (i.e., heteroskedasticity). Coefficient estimates remain unbiased in the presence of serial correlation and heteroskedasticity, but the estimates are no longer efficient, meaning that we may overestimate or underestimate the standard errors. In either case, any inferences we make using the estimates of standard errors are questionable. ${ }^{12}$

One commonly used remedy for these issues is to estimate a fixed effects model to account for cross-country differences, and to include a lagged dependent variable to correct for the serial correlation. However, such an approach is problematic for three reasons. First, estimating fixed effects to capture country-level differences can eliminate the majority of the crossnational variance, such that it can be difficult to estimate the effects of variables with little within-country variance (Huber and Stephens 2001). ${ }^{13}$ In addition, the use of a fixed effects model makes it impossible to estimate the effect of country-level variables that do not vary within countries over time (Wooldridge 2002). Therefore, we would be unable to estimate the effect of a factor like compulsory voting, which is an important predictor of voter turnout but is a factor for which we lack within-country variation in our sample. Second, Plümper et al. (2005) argue that the inclusion of a lagged dependent variable is problematic because it eliminates substantively meaningful trends in the dependent variable. Finally, Wooldridge (2002) demonstrates that the combination of these techniques-i.e., the use of fixed effects and a lagged dependent variable-may lead to inconsistent estimates.

Given these issues, we opt for an alternative approach. Specifically, we model voter turnout using a three-stage procedure developed by Plümper and Troeger (2005) refer to as fixed effects vector decomposition (FEVD). ${ }^{14}$ FEVD is preferable because it allows us not only to account for cross-country differences, but also to estimate the effect of time-invariant factors, such as compulsory voting. Moreover, using FEVD in combination with a PraisWinsten transformation (AR1) allows us also to address serial correlation 
OUP UNCORRECTED PROOF - FIRST PROOF, 29/9/2015, SPi

Jeffrey A. Karp and Caitlin Milazzo

Table 10.1. FEVD model of voter turnout, 1970-2011

\begin{tabular}{|c|c|c|}
\hline & Baseline model & Interactive model \\
\hline Globalization & $\begin{array}{r}-0.28^{*} \\
(0.12)\end{array}$ & $\begin{array}{c}-0.31^{\star *} \\
(0.12)\end{array}$ \\
\hline Global Finance Crisis & $\begin{array}{c}-0.25 \\
(1.61)\end{array}$ & $\begin{array}{l}15.98^{*} \\
(6.94)\end{array}$ \\
\hline Globalization*Global Finance Crisis & & $\begin{array}{r}-0.24^{\star} \\
(0.10)\end{array}$ \\
\hline Majoritarian & $\begin{array}{c}-13.37^{\star *} \\
(3.06)\end{array}$ & $\begin{array}{c}-13.95^{* *} \\
(3.00)\end{array}$ \\
\hline Compulsory Voting & $\begin{array}{l}8.13^{* *} \\
(3.06)\end{array}$ & $\begin{array}{l}8.12^{\star *} \\
(2.99)\end{array}$ \\
\hline Level of Democracy & $\begin{array}{c}1.86 \\
(2.39)\end{array}$ & $\begin{array}{l}1.84 \\
(2.40)\end{array}$ \\
\hline Established Democracy & $\begin{array}{l}14.71^{* *} \\
(2.89)\end{array}$ & $\begin{array}{l}14.77^{* *} \\
(02.85)\end{array}$ \\
\hline GDP & $\begin{array}{c}-0.08 \\
(0.11)\end{array}$ & $\begin{array}{c}-0.02 \\
(0.12)\end{array}$ \\
\hline Small Country & $\begin{array}{l}20.21^{* *} \\
(5.62)\end{array}$ & $\begin{array}{l}18.89^{\star *} \\
(5.56)\end{array}$ \\
\hline Intercept & $\begin{array}{l}79.49^{* *} \\
(9.87)\end{array}$ & $\begin{array}{l}81.33^{* *} \\
(9.84)\end{array}$ \\
\hline Observations & 486 & 486 \\
\hline Countries & 73 & 73 \\
\hline F-test & $8.54^{\star *}$ & $8.47^{* *}$ \\
\hline Adjusted $\mathrm{R}^{2}$ & 0.81 & 0.82 \\
\hline
\end{tabular}

Notes: Standard errors are given in parentheses. ${ }^{*} p<0.05,{ }^{\star *} p<0.01$.

within the model. The results are presented in Table 10.1. The baseline model, given in column 1, demonstrates that the turnout-depressing effect of globalization is not limited to advanced industrial democracies, but rather it extends across a large and diverse range of countries. The coefficient associated with globalization is negative and statistically significant, indicating the countries with greater economic integration tend to exhibit lower levels of voter turnout. The results of the interactive model, which includes the economic crisis variable and the interaction, are presented in column 2. Note that the coefficient associated with the main effect of globalization (the effect of globalization before the global financial crisis) remains negative and statistically significant. The effects associated with the global financial crisis beginning in 2008 are consistent with the idea that the presence of a major economic crisis heightens the turnout-depressing effect of globalization. The coefficient associated with the main effect of the crisis-Global Financial Crisis-is positive, while the coefficient associated with the interaction with globalization is negative. Taken together, these coefficients suggest that the crisis promoted turnout in countries where there was less economic integration, but that the crisis amplified the turnout-depressing effect of globalization in countries where economic integration is high. 
To illustrate the substantive effect of the financial crisis, we calculate the expected turnout at varying levels of globalization before and during the crisis. Figure 10.2 illustrates the effect of each period graphically. The solid black line represents the predicted turnout before the global financial crisis, while the dashed line represents the predicted turnout during the crisis. ${ }^{15}$ The predicted values indicate that at lower levels of globalization, the global financial crisis promoted turnout. At low levels of globalization, the average is 6 percentage points higher during the crisis (increasing from 86 to 92 per cent). However, at high levels of globalization, turnout was lower in elections that occurred during the crisis. Thus, the predicted values indicate that increasing globalization leads to a more pronounced decline in turnout in elections that took place during the global financial crisis.

\subsubsection{Supplementary Analyses}

The analyses presented in Table 10.1 rely on the composite index of globalization compiled by the KOF Swiss Economic Institute (Dreher et al. 2008b). However, the composite index is comprised of three separate indices that include a series of economic, political, and social indicators of globalization.

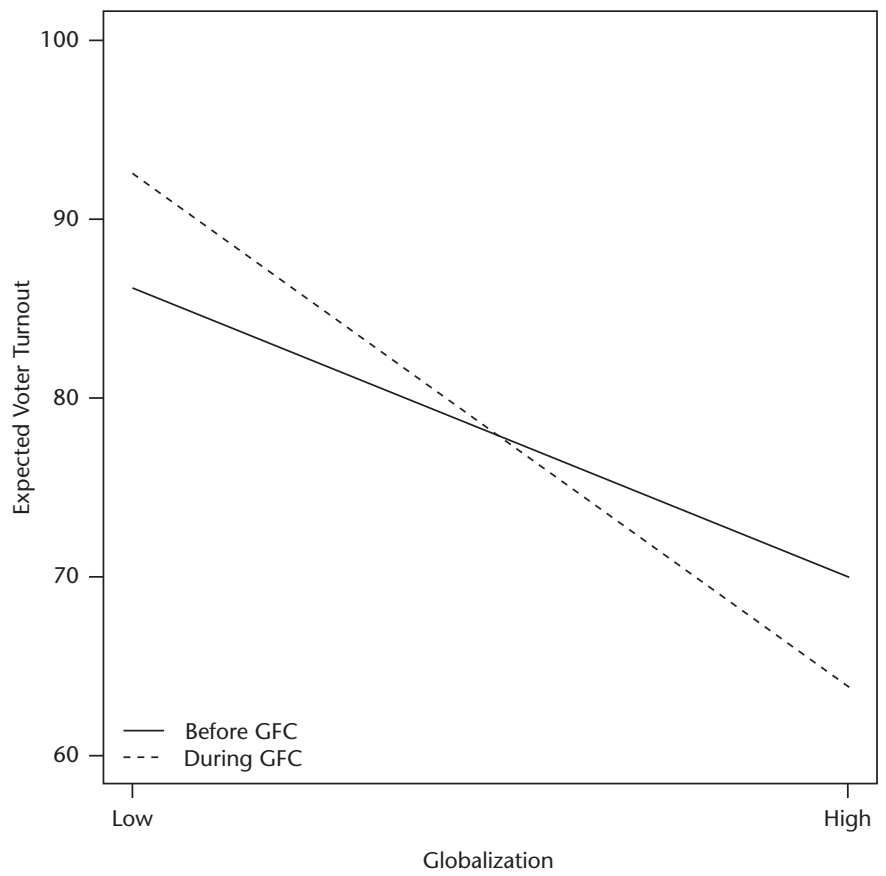

Figure 10.2. The predicted effect of globalization on aggregate turnout Note: Estimates derived from Table 10.1. 
OUP UNCORRECTED PROOF - FIRST PROOF, 29/9/2015, SPi

Jeffrey A. Karp and Caitlin Milazzo

Table 10.2. FEVD model of voter turnout using different measures of globalization

\begin{tabular}{llll}
\hline & $\begin{array}{l}\text { Economic } \\
\text { Globalization }\end{array}$ & $\begin{array}{l}\text { Political } \\
\text { Globalization }\end{array}$ & $\begin{array}{l}\text { Social } \\
\text { Globalization }\end{array}$ \\
\hline Globalization & $-0.22^{*}$ & -0.14 & -0.11 \\
Global Finance Crisis & $(0.11)$ & $(0.08)$ & $(0.10)$ \\
& 8.06 & $10.58^{*}$ & 3.33 \\
Globalization*Global & $(10.25)$ & $(5.29)$ & $(5.61)$ \\
Finance Crisis & -0.13 & $-0.14^{*}$ & -0.07 \\
Majoritarian & & & \\
& $(0.14)$ & $(0.07)$ & $(0.09)$ \\
Compulsory Voting & $-13.89^{* *}$ & $-12.16^{* *}$ & $-11.41^{* *}$ \\
& $(3.37)$ & $(2.89)$ & $(3.01)$ \\
Level of Democracy & $8.04^{*}$ & $8.98^{* *}$ & $7.80^{* *}$ \\
Established Democracy & $(3.23)$ & $(3.02)$ & $(0.09)$ \\
GDP & 1.96 & 2.46 & 2.48 \\
& $(2.57)$ & $(2.37)$ & $(2.26)$ \\
Small Country & $13.09^{* *}$ & $14.58^{* *}$ & $14.15^{* *}$ \\
Intercept & $(3.12)$ & $(2.84)$ & $(2.94)$ \\
Observations & -0.07 & -0.13 & -0.12 \\
Countries & $(0.10)$ & $(0.09)$ & $(0.11)$ \\
F-test & & $18.99^{* *}$ & $24.12^{* *}$ \\
Adjusted R & & $(5.99)$ & $(5.25)$ \\
\hline
\end{tabular}

Notes: Standard errors are given in parentheses. ${ }^{*} \mathrm{p}<0.05,{ }^{* *} \mathrm{p}<0.01$.

As a robustness check, we re-estimate our main models using each of the separate components of the globalization composite index. Table 10.2 presents three models, each of which incorporates a different dimension of globalization. Note that in all three models the signs of coefficients mirror those presented in Table 10.1. In each case, the coefficient associated with the measure of globalization (i.e., the effect of globalization before the global financial crisis) is negative, indicated that increasing levels of economic, social, and political globalization are all associated with a decrease in turnout. However, only in the case of economic globalization does the coefficient reach conventional levels of statistical significance.

Moreover, in all three models, the coefficient associated with the global financial crisis is positive, while the coefficient associated with the interaction is negative. Once again, these estimates provide evidence that the presence of an economic crisis enhances the turnout-depressing effect of globalization. However, the effects are only statistically significant with regards to political globalization. These findings may provide further support for the idea that globalization depresses voter turnout because voters perceive that parties and 
governments are unable to address economic policy issues (Hellwig and Samuels 2007; Steiner 2010; Marshall and Fisher 2011).

\subsection{The Global Financial Crisis and Changes in Individual Participation}

The analyses presented thus far suggest that economic crisis and, in particular, the recent global financial crisis may depress turnout in countries with high levels of economic integration. However, these analyses do not indicate which citizens are most affected by worsening economic conditions. To examine this question we rely on survey data from national election studies that included a common module of questions developed for the CSES. In order to examine how the global financial crisis affected behaviour, our analysis is restricted to those countries that fielded the module in 2008 or later. As a more rigorous test, we limit our analysis to those countries that also fielded the module prior to the financial crisis so that we have a basis for comparison with previous elections. This leaves us with twenty-six elections in ten countries. ${ }^{16}$

Reported turnout is measured by a question asking respondents whether they cast a vote in the election. It is well known that survey respondents may misreport participation. In particular, those who did not vote are likely to misreport voting in order to provide a socially desirable response (Ansolabehere and Hersh 2012), which could also vary across countries depending on levels of turnout (Karp and Brockington 2005). In formulating the question used to ascertain this information, collaborators were requested to try to ask the question in a way that minimizes over-reporting of voter turnout where this is known to be a problem. For example, in France, respondents were asked, 'For one reason or another, lots of people abstain from voting in the first round of a presidential election. Did you, personally, vote in the first round of the presidential election, on last April 21?' Nevertheless, reported turnout in these countries often exceeds actual turnout, which means that our results provide a conservative test of the hypotheses as we are likely to underestimate the effects of the economy on turnout.

First, we create an index to identify those who are most economically vulnerable. The index is made up of four dichotomous variables that include income, employment status, union membership, and marital status. The index is based on the assumption that any one of these characteristics, when combined with another, places a citizen at more risk. We rely on reported household income and identify the poorest citizens as those who are in the two lowest quintiles. ${ }^{17}$ Those who are in the labour force but not working are classified as unemployed. We assume that citizens who are not 
members of a union are more likely to be at risk. In addition, we assume that those who are single, all other things being equal, are likely to be more vulnerable than married couples because they must rely on one income base and one set of skills as opposed to married couples who have more potential and capacity to diversify in an economic downturn. Vulnerable is a simple additive index that increases in value depending on how many of these conditions are met. Thus the most economically vulnerable person would be a single unemployed non-union member who has an income in the lowest quintile.

In addition, the module includes an open-ended question asking respondents to identify the most important problem or issue facing the country at the time of the election. To identify those with a concern over the economy, we constructed a dichotomous variable that takes on a value of ' 1 ' if the respondent mentioned any economic concerns as being the most important issue, for example the financial crisis, unemployment, rising prices, etc. The measure takes on a value of ' 0 ' if no economic issues were mentioned. Beyond economic perceptions, we also control for age, gender, and whether the respondent holds a university degree. Finally, we include a measure of attachment to political parties, following the expectation that those who feel close to a political party are going to be more engaged in the political process. Beyond these individual-level control variables, we also include two country-level variables that were important predictors of voter turnout in the aggregate models presented above, notably compulsory voting, and whether the country was an established democracy. ${ }^{18}$

To estimate the effects of the financial crisis, a dichotomous variable, Global Financial Crisis, is included in the model that represents the most current election in each country. In order to determine how the crisis affects the most vulnerable in the electorate, we interact vulnerability with the financial crisis variable. It is important to note that all of the countries included in the analysis are characterized by relatively high levels of globalization according to the KOF index. For example, the mean level of globalization for all countries included in our aggregate dataset was 62.90, with a range from 22.23 to 92.57. Of the ten countries included in the present analysis, Mexico has the lowest level of economic integration at 58.71, and yet it falls near the median level of globalization. ${ }^{19}$ The aggregate-level analysis presented above suggests that the presence of a major economic crisis amplifies the turnout-depressing effect of globalization in countries where economic integration is high. Given that our individual-level dataset consists solely of countries with relatively high levels of economic integration, we expect that the coefficient associated with Global Financial Crisis will be negative-i.e., the onset of the crisis will reduce citizens' incentives to participate in the political process. Moreover, if the crisis impacts those citizens who are most economically vulnerable more 
severely, then the coefficient associated with the interaction between Global Financial Crisis and Vulnerable should be negative as well.

Table 10.3 reports the results of multi-level logit model of voting behaviour in ten counties before and after the onset of the global financial crisis. The results provide evidence that the financial crisis depresses turnout among those most vulnerable. The baseline model, given in column 1, demonstrates the effect of the individual components of the vulnerability index. In each case, respondents who indicated they were a member of vulnerable group were less likely to vote. Column 2 presents the results of the interactive model, which includes the vulnerability index, as well as the interaction term. The coefficient associated with the main effect of the Vulnerable is negative and statistically significant, indicating that in elections prior to the global financial

Table 10.3. Multi-level logit model of the effects of the global financial crisis on the likelihood of voting

\begin{tabular}{|c|c|c|}
\hline & Baseline model & Interactive model \\
\hline Global Financial Crisis & $\begin{array}{l}-0.03 \\
0.03\end{array}$ & $\begin{array}{l}0.27 \\
(0.25)\end{array}$ \\
\hline Bottom Income Quintiles & $\begin{array}{l}-0.08^{* *} \\
(0.03)\end{array}$ & \\
\hline Unemployed & $\begin{array}{l}-0.43^{\star *} \\
(0.05)\end{array}$ & \\
\hline Single & $\begin{array}{l}-0.46^{* *} \\
(0.03)\end{array}$ & \\
\hline Not a Union Member & $\begin{array}{l}-0.38^{\star *} \\
(0.05)\end{array}$ & \\
\hline Vulnerable & & $\begin{array}{l}-0.29^{\star *} \\
(0.02)\end{array}$ \\
\hline Global Financial Crisis* Vulnerable & & $\begin{array}{l}-0.11^{\star *} \\
(0.03)\end{array}$ \\
\hline Female & $\begin{array}{l}-0.05 \\
(0.03)\end{array}$ & $\begin{array}{l}-0.04 \\
(0.03)\end{array}$ \\
\hline Age & $\begin{array}{l}0.01^{* *} \\
(0.00)\end{array}$ & $\begin{array}{l}0.02^{* *} \\
(0.00)\end{array}$ \\
\hline University Degree & $\begin{array}{l}0.44^{* *} \\
(0.05)\end{array}$ & $\begin{array}{l}0.38^{* *} \\
(0.04)\end{array}$ \\
\hline Close to Party & $\begin{array}{l}0.90^{* *} \\
(0.03)\end{array}$ & $\begin{array}{l}0.90^{* *} \\
(0.03)\end{array}$ \\
\hline Economy Important & $\begin{array}{l}0.07^{*} \\
(0.03)\end{array}$ & $\begin{array}{l}0.11^{* *} \\
(0.03)\end{array}$ \\
\hline Compulsory Voting & $\begin{array}{l}0.90^{* *} \\
(0.32)\end{array}$ & $\begin{array}{l}0.89^{*} \\
(0.39)\end{array}$ \\
\hline Established Democracy & $\begin{array}{l}0.48^{*} \\
(0.19)\end{array}$ & $\begin{array}{l}0.50^{*} \\
(0.25)\end{array}$ \\
\hline Intercept & $\begin{array}{l}1.12^{* *} \\
(0.16)\end{array}$ & $\begin{array}{l}0.74^{* *} \\
(0.23)\end{array}$ \\
\hline AIC & 31,982 & 31,262 \\
\hline $\mathrm{N}$ (Observations) & 39,016 & 39,016 \\
\hline N(Groups) & 24 & 24 \\
\hline
\end{tabular}

Notes: Standard errors are given in parentheses. ${ }^{*} \mathrm{p}<0.05,{ }^{* *} \mathrm{p}<0.01$ 
crisis, citizens with greater levels of economic vulnerability were less likely to vote. Moreover, the coefficient associated with the interaction between the crisis and economic vulnerability is also negative, which suggests that the onset of the crisis further depresses turnout among citizens most vulnerable to its effects. Put differently, those who are most vulnerable are significantly less likely to vote, and the gap widens even further in the elections held during the global financial crisis.

To illustrate the substantive effect of the global financial crisis, we calculate the predicted probability of voting for citizens at varying levels of economic vulnerability before and during the global financial crisis. Figure 10.3 illustrates the effect of vulnerability on the probability of voting in each period graphically. The predicted values for elections held prior to the onset of the crisis, depicted in Figure 10.3(a), indicate that individuals who are extremely vulnerable to economic conditions-i.e., individuals who are single, unemployed, non-union members, and who have an income in the lowest quartile-are 0.22 less likely to vote; the predicted probability for individuals who are not vulnerable is 0.84 versus 0.63 for those respondents are highly vulnerable. However, in the elections that take place during the crisis, the differences are more pronounced. Figure 10.3(b) presents the predicted values for elections that take place during the crisis. For respondents who are less economically vulnerable, the predicted probability that they report that they voted in the election is 0.87 . In contrast, for respondents who are highly vulnerable, the predicted probability is 0.57 .

\subsection{Conclusion}

These findings provide a sobering account of the effects of globalization on the democratic process. While some have argued that globalization can promote democratization and democratic values, it seems clear that it cannot reverse the long-term decline in turnout that has been observed in many countries over the last four decades. In the worst case, economic interdependence may actually be a contributing factor that fosters unequal participation. While globalization can promote economic growth it can also lead to economic crises that reverberate around the world. We find little evidence that serious economic concerns mobilize citizens to become more involved in the process. Instead, economic dislocation can create feelings of hopelessness, which appears to lead the most vulnerable citizens to withdraw from the political process.

Our analysis of voter turnout across a forty-year period in ninety-nine countries confirms previous findings that globalization is associated with lower levels of voter turnout. We also find some evidence that economic crises 


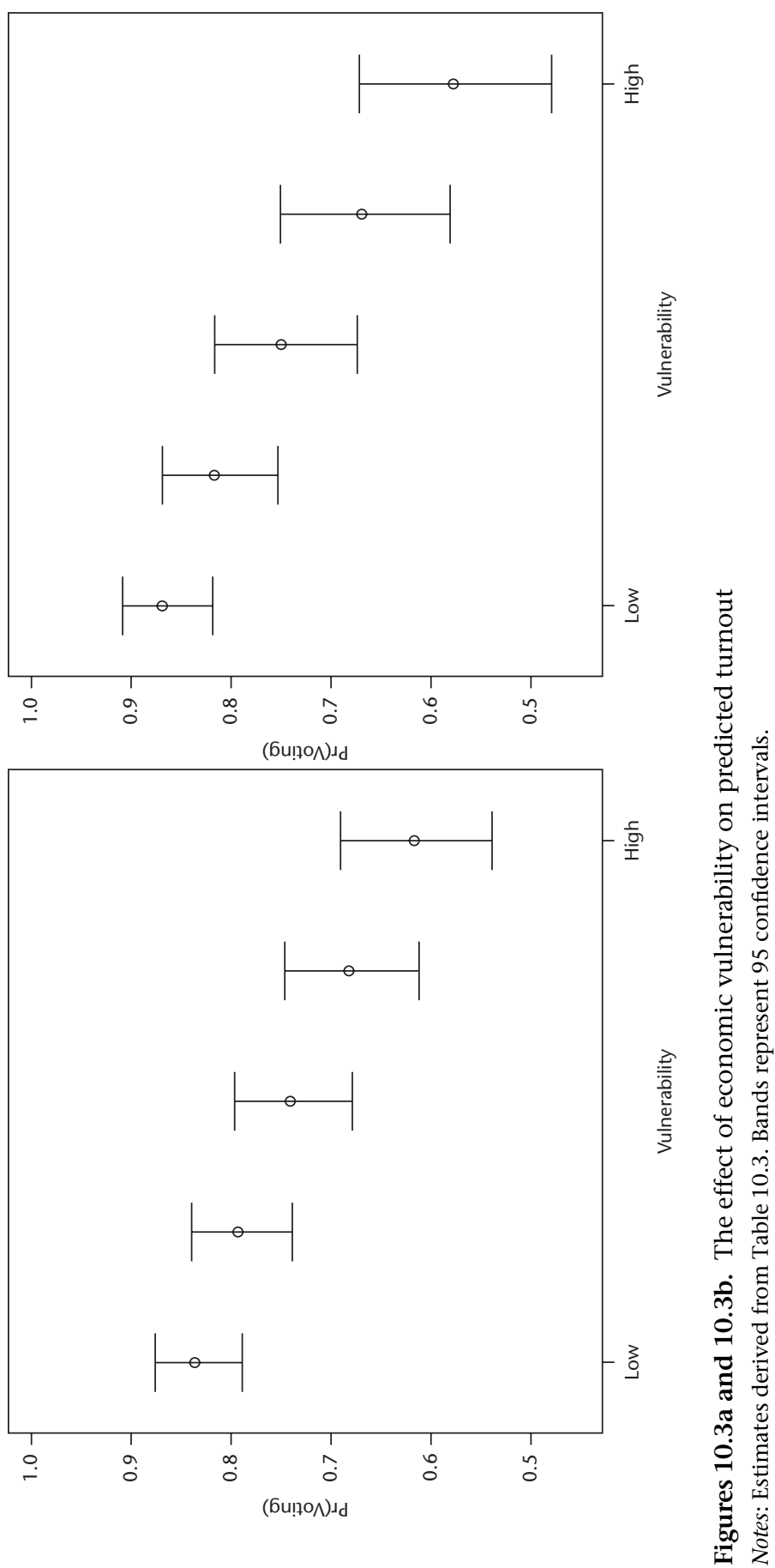


can depress turnout in certain contexts. Specifically, the global financial crisis appears to have depressed turnout in countries with high levels of economic integration. Our analysis of individual-level data suggests that the decline in turnout is most likely to be felt among certain subgroups in the population who are most vulnerable to changes in economic conditions, such as those who are low-income earners or the unemployed. Rather than being mobilized by economic crises, these individuals appear to withdraw from the political process. However there is also some evidence that citizens who are the least vulnerable may have been mobilized, which increases the bias in participation.

We believe our findings are important for two reasons. First, while a number of scholars document a negative relationship between globalization and voter turnout, these studies are limited to the analysis of a small number of advanced industrial democracies with similar economies. Therefore, we simply do not know how economic interdependence affects democratic participation in the vast number of countries where there are greater socio-economic differences. In contrast, our analyses incorporate elections from a wide range of countries, including new and established democracies, as well as developed and developing nations. Thus, the findings presented here provide evidence that the turnout-depressing effect of globalization is a generalizable phenomenon. Second, our work extends our knowledge of the effects of globalization by focusing on times of major economic crisis. The current financial crisis has affected (and will continue to affect) the lives of millions of citizens around the world. Therefore, it is important that we understand how these events shape how citizens perceive and participate within the political process.

\section{Appendix 10.1. Summary of Aggregate-level Turnout Data}

\begin{tabular}{lclclr}
\hline Country & $\begin{array}{c}\text { No. of } \\
\text { elections }\end{array}$ & Country & $\begin{array}{c}\text { No. of } \\
\text { elections }\end{array}$ & Country & $\begin{array}{c}\text { No. of } \\
\text { elections }\end{array}$ \\
\hline $\begin{array}{l}\text { Antigua and } \\
\quad \text { Barbuda }\end{array}$ & 2 & France & 9 & Palau & 2 \\
$\begin{array}{l}\text { Argentina } \\
\text { Australia }\end{array}$ & 11 & Germany & 11 & Panama & 4 \\
Austria & 16 & Ghana & 3 & Peru & 3 \\
Bahamas & 12 & Greece & 11 & Poland & 7 \\
Barbados & 7 & Grenada & 5 & Portugal & 13 \\
Belgium & 8 & Hungary & 6 & Romania & 4 \\
& 12 & Iceland & 11 & Sao Tome and & 6 \\
Belize & 6 & India & 8 & Principe & 2 \\
Botswana & 8 & Ireland & 11 & Slovakia & 5 \\
Brazil & 3 & Israel & 12 & Slovenia & 6
\end{tabular}


Globalization and Voter Turnout in Times of Crisis

\begin{tabular}{|c|c|c|c|c|c|}
\hline \multirow[t]{2}{*}{ Bulgaria } & 6 & Italy & 11 & South Africa & 4 \\
\hline & & Jamaica & 10 & South Korea & 6 \\
\hline Canada & 13 & Japan & 13 & Spain & 11 \\
\hline Cape Verde & 5 & Kiribati & 2 & St Kitts and Nevis & 7 \\
\hline Chile & 5 & Latvia & 6 & St Lucia & 8 \\
\hline Costa Rica & 10 & Lithuania & 5 & $\begin{array}{l}\text { St Vincent and the } \\
\text { Grenadines }\end{array}$ & 8 \\
\hline Croatia & 4 & Luxembourg & 8 & Suriname & 3 \\
\hline Cyprus & 7 & Malta & 6 & Sweden & 12 \\
\hline Czech Republic & 5 & Mauritius & 9 & Switzerland & 10 \\
\hline Denmark & 15 & Mexico & 4 & Trinidad and Tobago & 8 \\
\hline Dominica & 7 & Mongolia & 5 & United Kingdom & 9 \\
\hline $\begin{array}{l}\text { Dominican } \\
\text { Republic }\end{array}$ & 6 & Namibia & 4 & United States & 20 \\
\hline El Salvador & 5 & Netherlands & 12 & Uruguay & 5 \\
\hline Estonia & 5 & New Zealand & 14 & Vanuatu & 6 \\
\hline Finland & 11 & Norway & 10 & & \\
\hline
\end{tabular}

Source: CSES Modules 1, 2, and 3.

\section{Notes}

1. We use the terms 'globalization' and 'economic interdependence' interchangeably.

2. For example, Freedom House classifies Argentina as free between 1985 and 1997. In 1998, Argentina was downgraded to 'partly free'. In 1999, Argentina regained its status as a free democracy. Therefore, we only include legislative elections that occurred after 1999.

3. This limitation makes intuitive sense given that we seek to compare levels of turnout before and after the financial crisis.

4. A full list of countries and the number of elections for each country included is presented in Appendix 10.1 at the end of this chapter.

5. Data on voter turnout was compiled by the International Institute for Democracy and Electoral Assistance (IDEA) and is available on its website.

6. For a full list of the indicators and their contribution to the overall index, see Dreher (2006), Dreher et al. (2008b).

7. The KOF index is only available up to 2010 . Therefore, in countries where the most recent election occurred in 2011, we use the level of globalization from 2010.

8. In supplementary analyses, we also control for the overall level of deindustrialization (i.e., the percentage of the labour force not employed in the agriculture or industrial sectors). We found no evidence that deindustrialization was a meaningful predictor of voter turnout in our sample of country/elections. Due to missing data, the inclusion of deindustrialization in the model limits our sample size significantly. Therefore, we opt to omit the variable from our subsequent analyses.

9. This coding scheme is consistent with the Freedom House classification, in which higher numbers indicate a lower quality of democracy.

10. We also test for non-stationarity (i.e., whether the time trends in the data vary over time within countries), but find no evidence that this is a concern. 


\section{Jeffrey A. Karp and Caitlin Milazzo}

11. Serial correlation (i.e., autocorrelation) occurs when the error term associated with an observation in one time period is correlated with the error of an observation in another time period.

12. For example, with positive serial correlation (when the errors in one time period are positively correlated with errors in the next time period), the OLS estimates of the standard errors will be smaller than the true standard errors.

13. For example, in our dataset there is limited within-country variation in electoral institutions, because very few of the countries included in the dataset changed their electoral rules during this period. While we could attempt to estimate the effects of electoral rules using a fixed effects model, the standard errors are likely to be inefficient (Plümper and Troeger 2005).

14. See Plümper and Troeger $(2005,2011)$ for a detailed discussion of the FEVD model.

15. For all predicted values, we use the estimates from column 2 in Table 10.1. We set continuous variables to their mean and categorical variables to their median.

16. These country-elections are Brazil (2002, 2006, 2010), Iceland (2003, 2007, 2009), Germany (2002, 2005, 2009), Mexico (2003, 2006, 2009), New Zealand (2002, 2008), Portugal (2002, 2005, 2009), Slovenia (2004, 2008), South Korea (2004, 2008), Spain (2004, 2008), and Taiwan (2001, 2004, 2008).

17. About 13 per cent of the sample either claimed to not know or refused to report their household income. These cases are treated as missing. We also estimated models where missing values were set at the median value. The results did not change.

18. None of the countries included in our individual-level analyses use a majoritarian electoral system, nor do they have a population of less than 100,000.

19. The average level of globalization of the ten countries included in the analysis is 74.5 , which falls near the 75 th percentile of globalization. 